Claremont Colleges

Scholarship@ Claremont

Pomona Faculty Publications and Research

Pomona Faculty Scholarship

$1-12-2012$

\title{
Giving It Away: Sharing and the Future of Scholarly Communication
}

Kathleen Fitzpatrick

Pomona College

\section{Recommended Citation}

Kathleen Fitzpatrick. "Giving It Away: Sharing and the Future of Scholarly Communication." Planned Obsolescence. 12 Jan. 2012. Web. 13 Jan. 2012.

This Blog is brought to you for free and open access by the Pomona Faculty Scholarship at Scholarship @ Claremont. It has been accepted for inclusion in Pomona Faculty Publications and Research by an authorized administrator of Scholarship @ Claremont. For more information, please contact scholarship@cuc.claremont.edu. 


\section{PLANNED \\ OBSOLESCENCE}

falling indelibly into the past

\section{ABOUT KATHLEEN FITZPATRICK PROJECTS CATEGORIES ARCHIVES}

\section{JAN 2012 GIVING IT AWAY: SHARING AND THE FUTURE 10 COMMENTS OF SCHOLARLY COMMUNICATION}

The last talk I gave at MLA 2012 was a keynote for the Council of Editors of Learned Journals, the text of which is below. l'd love any feedback you might have to offer.

$-$

Giving It Away: Sharing and the Future of Scholarly Communication

As you might guess from my title, this presentation focuses in large part on questions of open access as they might affect our thinking about the future of scholarly communication. "Open access," I'm sure I don't need to tell you, is a fraught concept among both scholars and publishers, one beset by a lot of misunderstandings, both intentional and unintentional. Arguments circulate out there saying, for instance, that open access will open the floodgates to a lot of bad scholarship, when in fact open access publishing is perfectly compatible with peer review, and there are many OA journals that are more selective than their closed-access counterparts. There are folks who argue that open access is financially unsustainable, or even, as has been suggested by the recent proposal of the Research Works Act in Congress, an unreasonable infringement on publisher income, when in fact a range of new models for open access publishing are coming into being, and several of the major commercial journal publishers have recently announced new OA ventures, which they of course would never do if they hadn't found a business model in it somewhere. On the other hand, there are equally misguided convictions out there that open access publishing is free; clearly that's not so. What I am hoping to do in this talk, however, is to shift our thinking about open access, for the moment, from a focus on costs to a focus on values, though without entirely leaving behind the overwhelming and at times quite grim economic realities by which we're surrounded.

To begin, a bit of background: discussions of the possibilities for new open publishing models began online in the early 1990s, as a number of scientists and librarians recognized that the growth of the Internet made possible the free and open reproduction of scholarly literature. This is not to 
say that, even then, there was a conviction that OA publishing could be done for free; it was apparent to all of the players in these discussions that there would be continued costs involved in the production of the scholarly literature, but it was equally apparent that the costs of that literature's reproduction online would trend toward zero. Experiments such as Paul Ginsparg's pre-print server for papers in high-energy physics (which of course later developed into arXiv) as well as open challenges to the escalating subscription costs of STEM journals by projects such as BioMed Central and Public Library of Science began to suggest that there might be another path. Stevan Harnad pushed these discussions into the open by submitting what he called a "subversive proposal" to an email list in June 1994, in which he pointed out that "the scientific journal and the scholarly monograph are threatened by rising costs, rising output, and constrained academic budgets. The most painful paradox is that in the interests of science, the law of the market cannot be allowed to function. An item with a very small market may yet be the indispensable link in a chain of research that leads to a result of high social value." This is, in effect, the problem of the "long tail" in scholarly publishing; in traditional publishing, a few bestsellers provide financial support for the much less popular items on the list, those items down the tail that are extremely important to someone, though they're unlikely to reach a terribly large audience. The problem for us is that scholarly publications are all tail; practically the only audience for the stuff is the same group of scholars who are producing it - and yet, as Harnad pointed out, for those scholars, the work is indispensable. One means of escaping this paradox, Harnad suggested, was the creation of globally accessible electronic self-deposit archives of scholarly articles - the foundation of today's institutional and disciplinary repositories.

Over the years that followed Harnad's provocation, the guiding principles of the open access movement began to be articulated, leading to the Budapest Open Access Initiative published in 2002, which gave the movement its name. Following behind the Budapest initiative were the June 2003 Bethesda Statement on Open Access Publishing and the October 2003 Berlin Declaration on Open Access to Scientific Knowledge. Together, Budapest-Bethesda-Berlin defined the agenda for open access scholarly publishing:

By "open access" to this literature, we mean its free availability on the public internet, permitting any users to read, download, copy, distribute, print, search, or link to the full texts of these articles, crawl them for indexing, pass them as data to software, or use them for any other lawful purpose, without financial, legal, or technical barriers other than those inseparable from gaining access to the internet itself. The only constraint on reproduction and distribution, and the only role for copyright in this domain, should be to give authors control over the integrity of their work and the right to be properly acknowledged and cited. (BOAl)

"Open access," that is, means free access not just in the sense of "gratis," work made available without charge, but also in the sense of "libre" - work that, subject to appropriate scholarly standards of citation, is free to be built upon. This is the cornerstone of the scholarly project: scholarship is written to be read and to influence more new writing.

And this influence is the coin of the realm for scholars; the more influence that scholarship can produce, the better. Though lingering in the background of these early declarations was an 
awareness that open access publishing has the potential to "[give] authors and their works vast and measurable new visibility, readership, and impact" (BOAI), early mobilization around open access focused on the damage that a small number of corporate publishers who were accumulating vast numbers of scholarly journals were doing to university library budgets, as well as on the profound international economic inequities that functioned to create a growing divide between the information haves and have-nots. Open access presented the potential for scholars to help bridge this divide, serving not only their own interests in getting their work into broader circulation, but also serving the public good; as the Budapest Open Access Initiative put it,

An old tradition and a new technology have converged to make possible an unprecedented public good. The old tradition is the willingness of scientists and scholars to publish the fruits of their research in scholarly journals without payment, for the sake of inquiry and knowledge. The new technology is the internet. The public good they make possible is the world-wide electronic distribution of the peer-reviewed journal literature and completely free and unrestricted access to it by all scientists, scholars, teachers, students, and other curious minds. Removing access barriers to this literature will accelerate research, enrich education, share the learning of the rich with the poor and the poor with the rich, make this literature as useful as it can be, and lay the foundation for uniting humanity in a common intellectual conversation and quest for knowledge. (BOAl)

It's hard not to be moved by the idealism of a statement such as this, and easy to see why the movement's impact accelerated from here. The tenth anniversary of the Budapest Open Access Initiative is rapidly approaching; in the intervening decade, the open access movement spread through a dramatic increase in the number of OA journals (the "gold" model of open access), including the very public mass resignations of a number of editorial boards of closed-access journals, who then joined together to start new publications online. Additionally, the open access movement over the last decade was profoundly expanded through a growing number of institutional and disciplinary repositories (the "green" model of open access), as well as an increasing number of institution- and funder-based mandates requiring the deposit of the products of research done under their auspices. (It is of course those mandates that the Research Works Act seeks to attack.) By this past November, at Berlin 9, the ninth annual conference associated with the Berlin Declaration and the first to be held in the U.S., 34 North American signatories had endorsed the declaration and agreed to uphold its principles, including more than 20 colleges and universities. These signatories collectively produce a powerful demonstration of the expansion of U.S. commitment to facilitating open access, a commitment that can be seen at the national level in the recent White House Request for Information on Public Access to Digital Data and Scientific Publications.

[Here I noted that the deadline for responding to this RFI was upcoming -- today, in fact -- and urged the attendees to make their opinions known.]

Though these conversations, like the White House RFI, have to this point been overwhelmingly dominated by the sciences, the Berlin 9 conference took on as part of its focus this year the impact of open access on the humanities. While our fields bear certain interests in common with the 
sciences, there are a few important differences as well. The most obvious of these is a radical difference in funding systems and levels. Scientific research is all but impossible to conduct without large-scale grant funding, and scientists have long been able to write publishing costs into their grants. As a result, the business model for open access scientific publishing was relatively clear: shift from a reader-pays to an author-pays model. Easy-peasy. In the humanities, however, not only is the available funding generally too low to accommodate significant publishing charges to authors, but the vast majority of research is either supported by the scholar's institution or is self-funded.

It's for that reason that I'm not standing here suggesting that a large-scale transition of humanities publishing to an open access model would be easy; it wouldn't. Humanities publishing faces a set of financial constraints that are daunting at the best of times, and crushing in times of economic retraction. As I argue in Planned Obsolescence, it is of course perfectly well possible to make scholarly publishing profitable; the Wileys and the Elseviers have certainly managed it, but they've done so at the direct expense of our universities. For not-for-profit scholarly publishers to follow the commercial publishers' lead would for a range of reasons I explore in the book be a disaster. Those presses can't be beaten at their own game, as the large conglomerates that operate them will always be able to conduct business more efficiently, and more ruthlessly, than the university should want to do. But nor can we simply hand over the business of scholarly publishing to them to operate; as John Thompson noted in Books in the Digital Age, in times of economic slowdown "commercial logic would tend to override any obligation [such companies] might feel to the scholarly community" (98), leaving nothing to stop them from eliminating academic publishing entirely, if it ceases to pay. So we can't beat them, and we can't join them; what we can do is change the game entirely. And it's for this reason that I want to argue that, despite the serious difficulties involved, a transition to open access publishing might be desirable - desirable enough that rather than ending our conversations with the seeming insurmountableness of the financial obstacles, we should instead start figuring out what it will to take to get around them.

One thing that makes open access publishing so desirable for the future of scholarly communication is the increased impact that openly distributed scholarship is able to have, and study after study shows that open-access literature - whether that published in "gold" OA journals or that deposited in "green" OA archives - is more cited than is work published in traditional closed venues. In addition to facilitating traditional researcher access, however, openly published work can also reach a much broader range of readers - students and instructors at undergraduate teaching institutions and at secondary schools, for instance, as well as folks who work outside academia entirely. Open-access scholarship has the potential to reach a broad spectrum of potentially interested publics.

We in the humanities often resist opening our work to these publics, fearing the consequences of such openness - and not without reason. The world at times fails to understand what we do, and, because our subject matter seems as though it ought to be comprehensible (you're just writing about books, or movies, or art, after all!), isn't inclined to wrestle with the difficulties that our work presents; their dismissive responses give us the clear sense that the public doesn't take our work as seriously as, say, papers in high-energy physics, which few lay readers would assume their ability to comprehend without some background or training. As a result of these doubled misunderstandings, we close our work off from the public, arguing that we're only writing for a small group of specialists anyhow. In which case, why would open access matter?

The problem, of course, is that the more we close our work away from the public, and the more we 
refuse to engage in dialogue across the boundaries of the academy, the more we undermine that public's willingness to fund our research and our institutions. As Kathy Woodward put it so brilliantly on Friday, the major crisis facing the funding of higher education is an increasingly widespread conviction that education is a private responsibility rather than a public good; we wind up strengthening that conviction when we treat our work as private, by keeping it to ourselves. Closing our work away from non-scholarly readers, and keeping our conversations private, might protect us from public criticism, but it can't protect us from public apathy, a condition that is, in the current economy, far more dangerous. This is not to say that such openness doesn't bear risks, particularly for scholars working in controversial areas of research, but it is to say that only through open dialogue across the walls of the ivory tower will we have any chance of convincing the broader public, including our governmental funding bodies, of the importance of our work. And let me say this clearly: increasing the discoverability of scholarly work on the web, making it available to a broader readership, is a Good Thing, not just for the individual scholar but for the field in which she works. The more that well-researched, thoughtful scholarship on contemporary cultural issues is available to, for instance, journalists covering those issues for popular venues, the richer the discourse in those publications will become - increasing, not incidentally, the visibility of institutions of higher education, and their importance to the culture at large.

Even more important than its ability to foster this kind of impact, however, is the fact that open access publishing is far more in keeping with the core values of the scholarly enterprise. And this is where I really want to focus our attention, and where my title comes back in: giving it away. The notion of "giving it away" as l'm using it here comes to me from David Foster Wallace's Infinite Jest, and its rendering of the ethos of Alcoholics Anonymous:

Giving It Away is a cardinal Boston AA principle. The term's derived from an epigrammatic description of recovery in Boston AA: 'You give it up to get it back to give it away.' Sobriety in Boston is regarded as less a gift than a sort of cosmic loan. You can't pay the loan back, but you can pay it forward, by spreading the message that despite all appearances AA works, spreading this message to the next new guy who's tottered in to a meeting and is sitting in the back row unable to hold his cup of coffee. The only way to hang onto sobriety is to give it away (344)

This requirement of passing on what has been learned has its origins in the program's twelfth step, in which the recovering alcoholic carries the message to others who need it. The sharing that this sense of "giving it away" invokes - the loan that can never be paid back, but only forward - includes that sharing done at meetings, telling one's own story, not as a means of self-expression, but rather as an act of generosity that enables the addict to transcend the self. "Giving it away" is thus a profoundly ethical mode of engaging with others in need; more than that, in Infinite Jest, "giving it away" becomes the only means of escaping the self-destructive spiral of addiction and self-absorption that constitutes not an anomalous state, but in fact the central mode of being in the contemporary western world.

What I want to argue is that this sense of "giving it away," of paying forward knowledge that one likewise received as a gift, functions well as a description of what should be the best ethical practices of scholars and educators. We teach, as we were taught; we publish, as we learned from 
the publications of others. We cannot pay back those who came before us, but can only give to those who come after. Our participation in an ethical, voluntary scholarly community is grounded in the obligation we owe one another, an obligation that derives from what we have received.

Like the stirring sense in the Budapest Open Access Initiative of "uniting humanity in a common intellectual conversation and quest for knowledge," this kind of idealism is all well and good, but it doesn't adequately account for an academic universe in which we are evaluated based on individual achievement, and in which prestige often outstrips all other values. Surveys conducted both by Ithaka and by the Center for Studies in Higher Education at UC Berkeley indicate that "a fundamentally conservative set of faculty attitudes continues to impede systematic change" (Ithaka): scholars choose to publish in those venues that are perceived to have the highest influence on their peers, and that influence is often imagined to increase with exclusivity. The more difficult it is to get an article into a journal, the higher the perceived value of having done so, of course - but this sense of prestige too easily shades over into a sense that the more exclusively a publication is distributed, the higher its value. If we were simply to give our work away, it seems, its value would quickly trend toward zero.

This is, at its most benign, a self-defeating attitude; if we prize exclusivity above all else, we should not be surprised when our work fails to circulate. And in fact, it is when our work fails to circulate that its value declines; as Dave Parry has commented, "Knowledge which is not public is not knowledge." It is only in giving it away that we truly produce knowledge; it is only in escaping our self-absorption as a field, and instead of talking amongst ourselves, sharing our ideas with others, that we can pay forward the loan that we have been so generously given. Such an approach to our work, I would argue, requires less of a change than it might initially sound; all of the players in the scholarly communication chain - authors, reviewers, editors, publishers - are always engaged in a process of "giving it away"; it's just a matter of how and to whom. As a journal editor put it Thursday in the discussion at the session on the future of peer review, the entire enterprise runs on an engine of generosity. None of our work can ever truly be for profit; when we try to profit from it ourselves is precisely when we lose most profoundly.

Publishing is never free, of course; it either costs us in dollars or in labor (and often both), and sustainability in scholarly publishing has often been equated with the need to produce revenue based on the sale of publishing's products. As I've argued at length, however, the current system of scholarly publishing is already not sustainable for most not-for-profit organizations, and some of the ostensible solutions - such as handing journals over to the commercial publishers who seem to have found a viable profit model - are only making things worse. One might see here the cautionary tale of a fellow humanities scholarly organization that, facing a budgetary crisis, contracted with a commercial publisher to distribute its journals. That organization received a nice bit of income in the short term - but the commercial publisher involved immediately more than doubled the institutional subscription fees for the journals involved, ensuring that more libraries would be forced not to carry those journals, and thus reducing the potential impact of the work published in them. And needless to say, however much the organization involved earned in this exchange, the corporate publisher earned more.

So rather than giving our work away to corporate entities that will profit at our expense, might we instead find a way to make a virtue of our market failures? What if we understood sustainability not as the ability to produce revenue, but the ability to keep the engine of generosity running? What if we were to allow the engine of generosity on which so much of the enterprise runs to affect the final 
point of distribution, if we were to embrace the gift economy of scholarly communication and make a gift of our work to others? What might happen if outreach, generosity, giving it away were our primary values?

Such ethics need not be economically unsustainable. Larry Lessig has argued at length that the most successful potential business model of the digital age is not the sale of closed, proprietary content, but instead the "hybrid" model under which so much of contemporary online communication operates: the production of content is freely done by users; the distribution of content is provided equally freely by the company; but the company charges for certain kinds of services surrounding that content, whether premium tools for engaging with that content or additional space for storing that content or what have you. This so-called "freemium" model underwrites services including Flickr, Dropbox, WordPress, and a range of other internet-based communication tools. In all of these systems a basic level of access is provided for free, while value is created through services or tools; with Flickr, for instance, the value the company provides comes not from the site's wealth of photographic content - users provide that, and are able to do so through a basic level of service available for free - but instead in providing access to a suite of tools that allow users to share, tag, search, connect, and so forth. The value in the system, which users are willing to pay for, is the means of interacting with the content, rather than the content itself. Such a model works best for user-generated content - and of course all scholarly communication is "user-generated," created to be shared, producing the most substantive benefits for its authors when its distribution is as broad and as open as possible.

I want to return to the sense that I mentioned a few minutes ago in which all of us in the scholarly communication chain are always engaged in the process of "giving it away": scholarly authors write in order to get their ideas into circulation within their fields, and, like many musicians today, are paid not for their publications but for their performances, whether in the classroom or on the lecture circuit. But it is not only scholars who give their work away: peer reviewers do so as well. In journal publishing, reviewers provide their services on a purely volunteer basis; the only compensation comes in the ability to help shape the future of the fields they care about. Bonnie Wheeler has noted the mounting difficulties, of course, in getting reviewers to do this work, and it appears that under the current system, reviewer resistance is bound to grow. There is a strong movement afoot encouraging peer reviewers to reserve their volunteer labor for publications that make the results of that work freely and openly available; if the journal publishing system runs in part on the engine of reviewer generosity, it would serve us well to respond to that generosity by paying it forward.

The system also runs on the engine of editor generosity; journal editors, as you all know better than anyone, donate tremendous amounts of time and effort to enabling and improving communication within their fields, usually with a bare minimum of reward and increasingly without institutional support. What would it be to pay forward such editor generosity, and to create an environment in which the value created by such editors, as well as the values they espouse, were allowed to proliferate?

Similarly, not-for-profit publishers are committed to facilitating the circulation of the products of scholarly research, but are constrained by the need to do so sustainably if they are to survive. What would it be for such publishers to create systems within which authors, reviewers, and editors were able to pay forward what they have received, to give their work to one another and to the public beyond? What would it be for publishers to give all of that content away, and to focus their work on developing advanced services for interacting with that content, and with the community? 
Making such a transition from a focus on content-for-sale to a focus on services and tools cannot be made without similar generosity on the part of our foundations and our federal granting agencies. Those granting agencies are beginning to think about how they might support scholarly communication as it becomes more open, but those agencies can only do so much; we have to be sure the engine they help us build can continue to run. As such, universities must "recognize," in the words of a recent Ithaka report, "that publishing is an integral part of [their] core mission and activities," and respond by supporting those engines of generosity on their campuses, knowing that such generosity will be paid forward in increased visibility, and increased goodwill. Donald Hall has argued that the future viability of higher education requires that we collectively reclaim the intellectual growth fostered in the academy as a public good rather than a private responsibility. If we ask this of our institutions, and our funders, we must also ask it of ourselves.

There are financial realities that must be acknowledged in all of this, and I don't want to minimize the difficulties of grappling with them. But in all such discussion about such financial realities, I cannot help but remember something Michael Jensen of the National Academies Press once told me. The NAP makes all of its publications freely and openly available on the web, producing revenue by selling print versions of that content. Admittedly, NAP has probably lost revenue that it could have obtained if it had refrained from giving the work it publishes away online - but it has gained significantly in visibility, in discoverability, and in goodwill. As Jensen said, when I asked him about this model, the press's mandate is to make as much of its work available as freely and openly as it can while still breaking even. And this is the ethos that I would love to see become the guiding principle for scholarly communication more generally.

How much can we make freely and openly available in this fashion? How might we reimagine the production of revenue in scholarly communication from a basis in the sale of content to a basis in the provision of services? How can we work together to reorient our perspective from costs to values? How might openness allow us to better engage not just with one another but with the world around us, treating that world not just as an object laid open to our masterful scrutiny, but instead as a complex conglomeration of agents both able and entitled to enter into conversation with us? What if we were to recognize that the only way to hold onto the knowledge we have - and to help higher education and the communities within which we work to thrive - is to give it away?

Tweet $44 \quad$ Facebook Email 